\title{
Seasonal variations in Plasmodium falciparum genetic diversity and multiplicity of infection in asymptomatic children living in southern Ghana
}

\author{
Joshua Adjah, Bless Fiadzoe, Ruth Ayanful-Torgby and Linda E. Amoah* ${ }^{*}$
}

\begin{abstract}
Background: Genetic diversity in Plasmodium falciparum (P. falciparum) parasites is a major hurdle to the control of malaria. This study monitored changes in the genetic diversity and the multiplicity of $P$. falciparum parasite infection in asymptomatic children living in southern Ghana at 3 month intervals between April 2015 and January 2016.

Methods: Filter paper blood spots (DBS) were collected quarterly from children living in Obom, a community with perennial malaria transmission and Abura, a community with seasonal malaria transmission. Genomic DNA was extracted from the DBS and used in polymerase chain reaction (PCR)-based genotyping of the merozoite surface protein 1 ( $m s p$ 1) and merozoite surface protein 2 (msp 2) genes.

Results: Out of a total of 787 samples that were collected from the two study sites, 59.2\% (466/787) tested positive for P. falciparum. The msp 1 and msp 2 genes were successfully amplified from 73.8\% (344/466) and 82.5\% (385/ 466) of the $P$. falciparum positive samples respectively. The geometric mean $\mathrm{MOI}$ in Abura ranged between 1.17 (95\% Cl: 1.08-1.28) and 1.48 (95\% Cl: 1.36-1.60) and was significantly lower ( $p<0.01$, Dunn's multiple comparison test) than that determined in Obom, where the geometric mean $\mathrm{MOI}$ ranged between 1.82 (95\% Cl: 1.58-2.08) and 2.50 (95\% Cl: 2.33-2.678) over the study period. Whilst the msp 1 R033:MAD20:Kl allelic family ratio was dynamic, the msp 2 3D7:FC27 allelic family ratio remained relatively stable across the changing seasons in both sites.

Conclusions: This study shows that seasonal variations in parasite diversity in these communities can be better estimated by $m s p 1$ rather than msp 2 due to the constantly changing relative intra allelic frequencies observed in msp 1 and the fact that the dominance of any msp 2 allele was dependent on the transmission setting but not on the season as opposed to the dominance of any msp 1 allele, which was dependent on both the season and the transmission setting.
\end{abstract}

Keywords: Asymptomatic, Malaria, Allele, msp 1, msp 2, Genetic diversity, Multiplicity of infection

\section{Background}

The high prevalence of malaria in Ghana has resulted in a majority of adults and children older than 5 years attaining a semi-immune status due to past and continuous exposure to different parasite clones [1]. Repeated exposure to a particular parasite clone is said to offer protection from clinical episodes of malaria caused by that parasite clone, which may result in asymptomatic

\footnotetext{
* Correspondence: lamoah@noguchi.ug.edu.gh

Department of Immunology, Noguchi Memorial Institute for Medical Research, University of Ghana, Accra, Ghana
}

carriage of that clone by the host [2,3]. The multiplicity of infection (MOI), which identifies the number of clones within a particular infection can serve as a measure of the level of malaria transmission as well as identify hotspots within very low transmission settings $[4,5]$. Within-host parasite diversity at the population level and the dynamics of diversity are important in malaria eradication efforts [6,7]. Malaria parasite diversity is distinct in different individuals, populations, transmission settings and seasons within endemic zones and changes with variations in parasite prevalence [5], and

(c) The Author(s). 2018 Open Access This article is distributed under the terms of the Creative Commons Attribution 4.0 International License (http://creativecommons.org/licenses/by/4.0/), which permits unrestricted use, distribution, and reproduction in any medium, provided you give appropriate credit to the original author(s) and the source, provide a link to the Creative Commons license, and indicate if changes were made. The Creative Commons Public Domain Dedication waiver (http://creativecommons.org/publicdomain/zero/1.0/) applies to the data made available in this article, unless otherwise stated. 
has been suggested to be constantly changing [8-11]. Parasite genetic diversity and MOI studies have also been found to be important in the surveillance of strains circulating in a particular transmission area. The identification of hotspots are important in understanding the epidemiology of $P$. falciparum infections for informed interventions to be instituted [5, 12, 13]. There have been reports of extensive genetic diversity of $P$. falciparum in high transmission areas with some infected people harboring multiple clones of the parasites. On the contrary, people living in low transmission areas tend to have low genetic diversity with a high proportion being monoclonal infections [14-17]. Transmission intensity and efficiency vary significantly between malaria endemic areas and is dependent on several factors including varying mosquito populations, changes in parasite-vector interactions due to temperature changes, hosts' immunological changes induced by parasite interaction and the spatial heterogeneity over which these occur $[18,19]$. Thus, understanding the population and within-host diversity of the malaria parasite in distinct geographic locations with varying malaria transmission patterns across changing malaria seasons, may help identify control measures that are appropriate for a particular transmission setting at a specific time of the year [20].

The most common and widely used tool for the estimation of parasite diversity is PCR based genotyping of a gene with high diversity such as merozoite surface protein 1 (msp 1, PF3D7_0930300), merozoite surface protein 2 (msp 2, (PF3D7_0206800) and the glutamate-rich protein (glurp, PF3D7_1035300) [21-25]. The use of PCR to derive the number of repeat length variants observed at the highly diverse loci of the $m s p 1$ and $m s p 2$ genes helps to measure MOI and transmission in a population. Although only a limited number of loci can be examined at a time and some minor parasite populations missed by conventional PCR $[5,26]$ compared to more sensitive tools including SNP typing, conventional PCR followed by agarose gel electrophoresis remains an easier, quicker and a more cost effective way to adequately genotype different parasite clones [27]. Many recent studies on parasite diversity, especially in poorly resourced settings that cannot afford to use the enhanced genotyping tools, which are relatively more expensive continue to utilize $m s p$ genotyping followed by agarose gel electrophoresis as their parasite diversity analysis tool [28-31].

The genetic diversity of $P$. falciparum circulating in the middle belt of Ghana has been extensively characterized [32, 33]. However, diversity studies on parasites circulating in southern Ghana have been limited to selected time points in asymptomatic $[27,31]$ or in symptomatic infections $[34,35]$. This study sought to identify changes in infecting parasite MOI and genetic diversity in asymptomatic children living in different malaria transmission settings over the course of changing malaria transmission seasons. This data would help in the selection and design of appropriate intervention tools that can be deployed during the different transmission seasons.

\section{Methods \\ Study site}

The study was conducted in community primary schools in two areas of southern Ghana; Obom, a semi-rural community in the Ga South Municipality of the Greater Accra Region with high and perennial malaria transmission and Abura, a semi-urban community in the Cape Coast Municipality of the Central Region with low and seasonal malaria transmission [36]. In 2010, the Ghana Statistical Services identified higher levels of overcrowding in sleeping rooms as well as a higher prevalence of liquid waste disposal in the compounds and streets than into drains and gutters in the Ga South municipality than in the Cape Coast Metropolis [37, 38]. The Cape Coast Metropolis also has fewer illiterate inhabitants than the Ga South District [37, 38]. Both study sites lie in the coastal savannah belt of Ghana (Fig. 1) and have most infections occuring in the major rainy season that peaks between June and August. Plasmodium falciparum parasite prevalence in Obom has been noted to be higher than in Abura [36, 39].

\section{Sample collection}

After obtaining parental consent, 237 children between the ages of 6 and 12 years were recruited in a multiple cross sectional study; 83 from Obom and 154 from Abura. Filter paper (Whatman $3 \mathrm{~mm}$ ) blood spots (DBS) were prepared from $\sim 50 \mu \mathrm{L}$ of finger pricked blood that was collected in April, June and October 2015 as well as in January 2016. The filter paper blots were air-dried and stored desiccated at room temperature. None of the children sampled exhibited any signs or symptoms of clinical malaria at the time of blood draw and were classified as either healthy with no PCR detectable parasites or asymptomatic, harboring PCR detectable P. falciparum parasites. The same children were followed up during subsequent sampling visits.

\section{Extraction of parasite DNA}

Total genomic DNA (gDNA) was extracted from the dried blood spot (DBS) using the Chelex extraction procedure $[40,41]$. Briefly, two $3 \mathrm{~mm}$ discs were punched out from the dried blood spots into $1.5 \mathrm{~mL}$ microcentrifuge tubes containing $1 \mathrm{~mL}$ of $1 \mathrm{X}$ phosphate buffered saline (PBS). The discs were washed twice in $1 \mathrm{~mL}$ PBS and then boiled at $99^{\circ} \mathrm{C}$ in $200 \mu \mathrm{L}$ of $20 \%$ Chelex (Sigma-Aldrich, USA) in DNase/RNase-free water. After a final centrifugation step $(14,000 \times g$ for $1 \mathrm{~min})$, the extracted DNA was transferred 


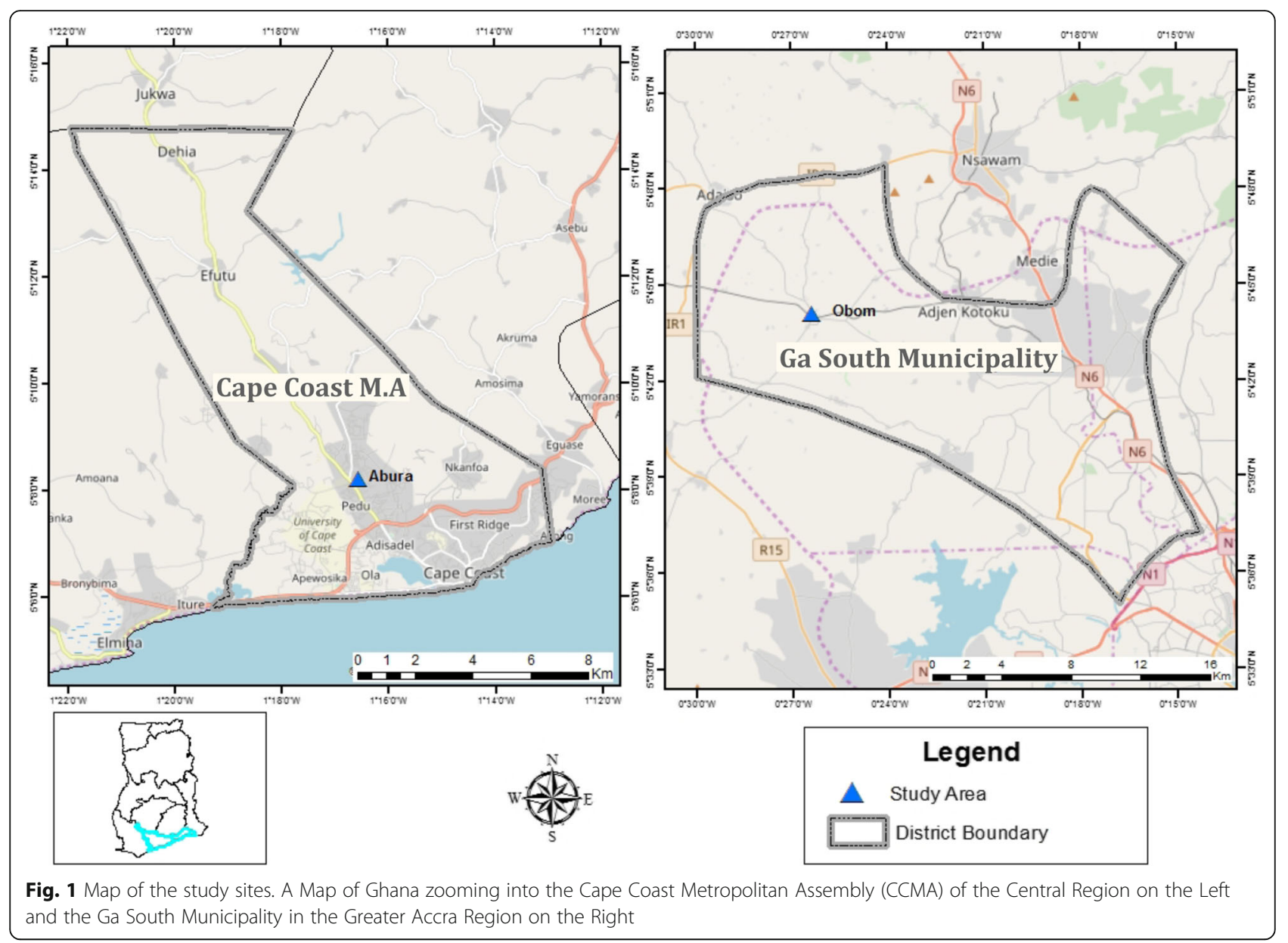

into a labelled $0.6 \mathrm{~mL}$ microcentrifuge tube and then stored at $-20{ }^{\circ} \mathrm{C}$.

\section{Molecular detection of $P$. falciparum parasites}

A nested PCR amplification protocol based on amplification of the small subunit ribosomal RNA (18S rRNA) gene was used to detect $P$. falciparum [42]. The $15 \mu \mathrm{L}$ primary reaction mixture contained $5 \mu \mathrm{L}$ of DNA $(\sim 10-50 \mathrm{ng})$, $2.5 \mathrm{mM} \mathrm{MgCl} 2,200 \mathrm{nM}$ dNTP mix, $200 \mathrm{nM} \mathrm{rPLU5}$ and rPLU6 primer set (Additional file 1) and 1 U OneTaq DNA polymerase (NEB, UK). The reaction cycling parameters comprised an initial 2 min denaturation at $94{ }^{\circ} \mathrm{C}$ followed by 35 cycles of $94{ }^{\circ} \mathrm{C}$ for $30 \mathrm{~s}, 54{ }^{\circ} \mathrm{C}$ for $1 \mathrm{~min}$ and $68^{\circ} \mathrm{C}$ for $1 \mathrm{~min}$, with a final $5 \mathrm{~min}$ extension at $68^{\circ} \mathrm{C}$. The secondary reaction mixture was similar to the primary; however, $2 \mu \mathrm{L}$ of the primary PCR product was used as DNA template and with rFal1 and rFal2 primer set (Additional file 1) used in the amplification. The cycling profile for the secondary PCR was similar to the primary PCR except for the annealing temperature which was increased from $54{ }^{\circ} \mathrm{C}$ to $59{ }^{\circ} \mathrm{C}$. A no template negative control and MRA-102G (3D7) and MRA-155G (HB3) positive controls were included in each set of PCR amplifications.

\section{Allelic genotyping of msp 1 and msp 2 genes}

The polymorphic regions of $m s p 1$ block 2 and $m s p 2$ block 3 were amplified using a protocol adapted from the $\mathrm{WHO}$ protocol for malaria parasite genotyping [43] and similar to that described by Ayanful-Torgby et al. [39, 44]. All PCR reactions were carried out in a total volume of $15 \mu \mathrm{L}$, containing $200 \mathrm{nM}$ dNTP mix, $2 \mathrm{mM} \mathrm{MgCl} 2,200 \mathrm{nM}$ each of forward and reverse primers for both msp 1 and msp 2 (M1-OF, M1-OR, M2-OF, M2-OR, Additional file 1) and 0.75 units of OneTaq Polymerase. Four microliters of extracted DNA $(\sim 10-50 \mathrm{ng})$ and $1 \mu \mathrm{L}$ of control genomic DNA $(10 \mathrm{ng} / \mathrm{mL})$ was used as template for the primary PCR reaction. The $15 \mu \mathrm{L}$ secondary PCR reactions contained a similar recipe as the primary reaction except that the template was $2 \mu \mathrm{L}$ of the primary PCR product and the primers used were M1-KF \& M1-KR, M1-MF \& M1-MR, RO33-F \& RO33-R, S1fw \& N5rev and S1fw \& M5rev (Additional file 1: Table S1). A no template negative control and positive controls for each allelic family (MRA-102G (3D7) for msp 2 3D7 alleles, MRA-159G (KI) for $m s p 1 \mathrm{KI}$ and $m s p 2$ FC27 alleles, MRA-155G (HB3) for msp 1 MAD20/msp 2 FC27 alleles and MRA-200G (R033) for msp 1 RO33/msp 2 3D7 alleles) were included 
in each set of PCR reactions. PCR products were resolved for an average of $50 \mathrm{~min}$ at $120 \mathrm{~V}$ on a $2 \%$ agarose gel stained with $0.5 \mu \mathrm{g} / \mathrm{mL}$ ethidium bromide. After the electrophoresis, the gels were visualized under UV trans-illumination using a Toyobo FAS-III gel doc system and then analyzed.

\section{Data analysis}

A sample containing a multiclonal infection produced more than one amplified fragment after either the three $m s p 1$ or the two msp 2 allelic family PCR reactions. A sample containing a clonal infection produced a single product after the three $m s p 1$ PCR reactions as well as a single product after the two $m s p 2$ reactions. A simplified method of estimating multiplicity of infection (MOI), where MOI of a sample was taken as the highest number of PCR products (amplicons) obtained after the family specific $m s p 1$ or $m s p 2$ PCR amplifications was used. Multiplicity of infection was generalized and reported as the geometric mean MOI for infections in the group of children from one study site at each time point.

The geometric mean, column statistics, unpaired $\mathrm{T}$ test and One-way analysis of variance were obtained using GraphPad Prism v5.0. The distribution of the different allelic families was presented as proportions. The frequency of $m s p 1$ and $m s p 2$ family alleles was calculated as the ratio of the number of PCR products obtained for each family to the total number of gene-specific PCR products identified. The MOI for msp 1 or $m s p 2$ in a sample was estimated as the total number of distinct $m s p$ 1 or msp 2 PCR amplicons detected in that sample, the total MOI of a sample is the highest number of PCR fragments obtained after both msp 1 and msp 2 genotyping $[39,45]$. A chi-square test as well a a Fishers exact test was performed using R3.3.2-win to determine possible relationships between the occurrence of any msp 1 and msp 2 allele at the different time points. Statistical significance was defined as $p$ value $\leq 0.05$ unless otherwise stated.

\section{Results}

At enrolment, there were 46.5 and $45.3 \%$ male children in Obom and Abura respectively. The mean (SEM) age of the children in Obom was 8.96 years, which was not significantly different $(p=0.8$, Unpaired T test) from the mean age of 9.10 years in Abura (Table 1). A number of children were lost to follow up mainly because the academic year ended in July and some of the children did not return back to school at the beginning on the new school year, thus the reduced numbers available during the October and January sampling (Additional file 2). Out of a total of 787 samples that were collected from the two study sites, 59.2\% (466/787) tested positive for
Table 1 Demographic data of participants involved in the study from the two sites

\begin{tabular}{lllc}
\hline & Obom & Abura & $P$ value \\
\hline Age-range (years) & $6-12$ & $6-12$ & \\
Mean age \pm SD & $8.96 \pm 0.17$ & $9.10 \pm 0.12$ & 0.8 \\
Geographic setting & semi-rural & semi-urban & \\
Average sex ratio (M:F) & $1: 1$ & $1: 1$ & \\
MOI $^{a}$ (GM) & 2.1 & 1.4 & $<0.0001$ \\
MOI (range) & $1.82-2.50$ & $1.17-1.48$ & \\
N & 83 & 154 &
\end{tabular}

MOI Multiplicity of Infection, GM Geometric mean (GM); Age range of children enrolled, $S D$ Standard deviation, $M / F$ Male to Female ratio, $N$ initial number of children enrolled

average of the four time points

P. falciparum (asymptomatic at the time of sampling). Asymptomatic parasite carriage over the course of the study was 41\% (197/481), ranging between 13.7\% (13/95) and 64\% (89/139) in Abura and 88\%, ranging between 80\% $(64 / 80)$ and $96.4 \%(80 / 83)$ in Obom (Additional file 2, Fig. 2) and was significantly higher at all time points in Obom than Abura (Mann-Whitney test; $\mathrm{U}=1400, p<0.0001$ at all time points).

\section{Dynamics of parasite multiplicity of infection}

The highest number of fragments obtained after either the msp 1 or $m s p 2$ gene amplifications was considered as the number of independent parasite clones co-existing within an infection and as the multiplicity of that infection. The $m s p 1$ and $m s p 2$ genes were successfully amplified from $73.8 \%(344 / 466)$ and $82.5 \%(385 / 466)$ of the P. falciparum positive samples respectively. The samples yielded amplicons compared to the $57.4 \%$ of asymptomatic samples that yielded products in Abura. The msp 2 amplification efficiencies were similar in both sites, 83\% (223/269) in Obom and 82.2\% (162/197) in Abura (Additional file 2). Amplification efficiencies for msp 1 was higher in Obom where $86 \%$ of the asymptomatic samples yielded amplicons compared to the $57.4 \%$ of asymptomatic samples that yielded products in Abura. The msp 2 amplification efficiencies were similar inboth sites, 83\% (223/269) in Obom and $82.2 \%(162 / 197)$ in Abura (Additional file 2). The geometric mean multiplicity of infection (MOI) was however estimated for the entire group of children from each of the study sites. The highest geometric mean MOI of 2.50 (95\% CI 2.33-2.68) in children from Obom occurred in October 2015 and was significantly higher $(p<0.01$, Dunn's Multiple Comparison test) than the lowest geometric mean MOI of 1.82 (95\% CI 1.58-2.08) at the same site, which occurred in January 2016 (Fig. 3). In Abura, the highest geometric mean MOI of 1.48 (95\% CI 1.36-1.60), which occurred in July 2015 was not significantly different from the lowest, 1.17 (95\% CI 1.08-1.28) 


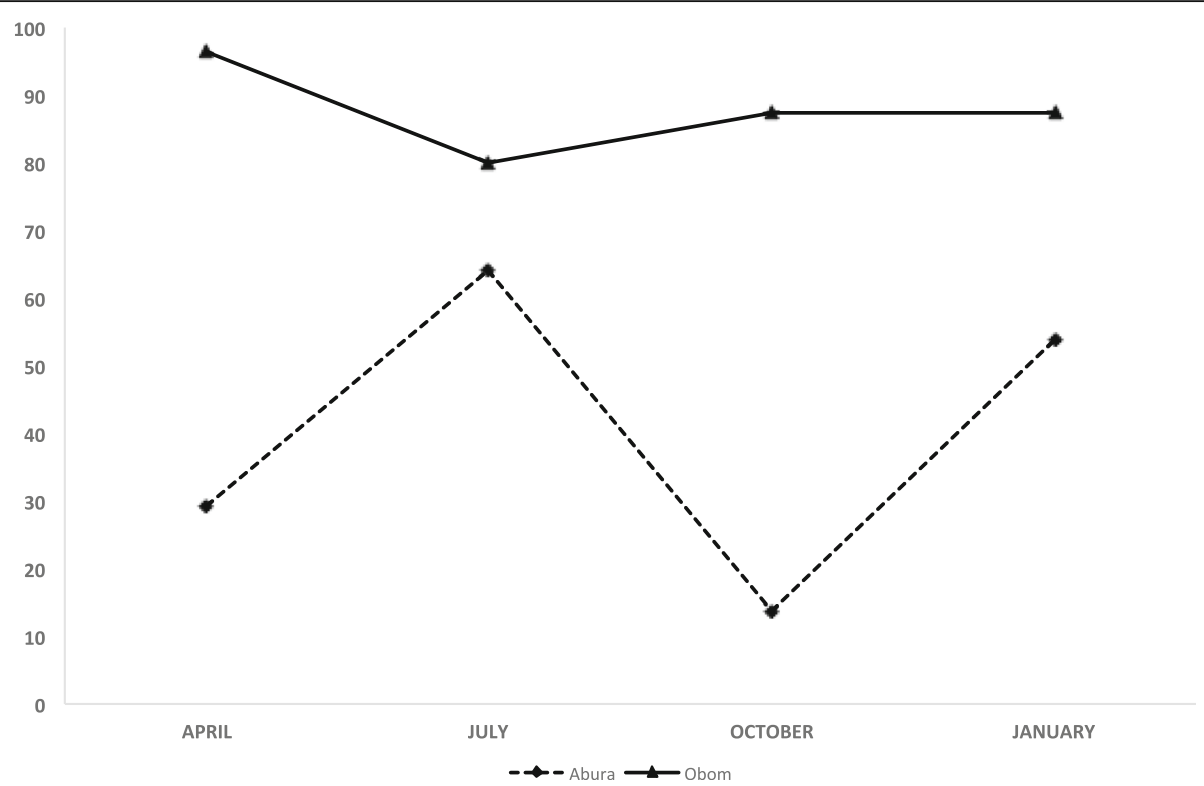

Fig. 2 Prevalence of asymptomatic children. Comparison of asymptomatic parasite carriage in Abura (broken line), a low malaria transmission setting and Obom (solid line), a high malaria transmission setting in April, July, October and January (which represent the different malaria transmission seasons pre peak, peak, end of peak and off peak respectively)

in January 2016 ( $p>0.05$, Dunn's Multiple Comparison test) (Fig. 3). The geometric mean MOI in asymptomatic children from Obom was always significantly higher than those in children from Abura during each visit $(p<0.001$ at each time point, Mann Whitney Test).
Dynamics of parasite genetic diversity

The presence of an amplified product after a family-specific PCR was used to categorize the parasites contained in a sample as belonging to that particular allelic family. A number of children were infected with multiple parasite

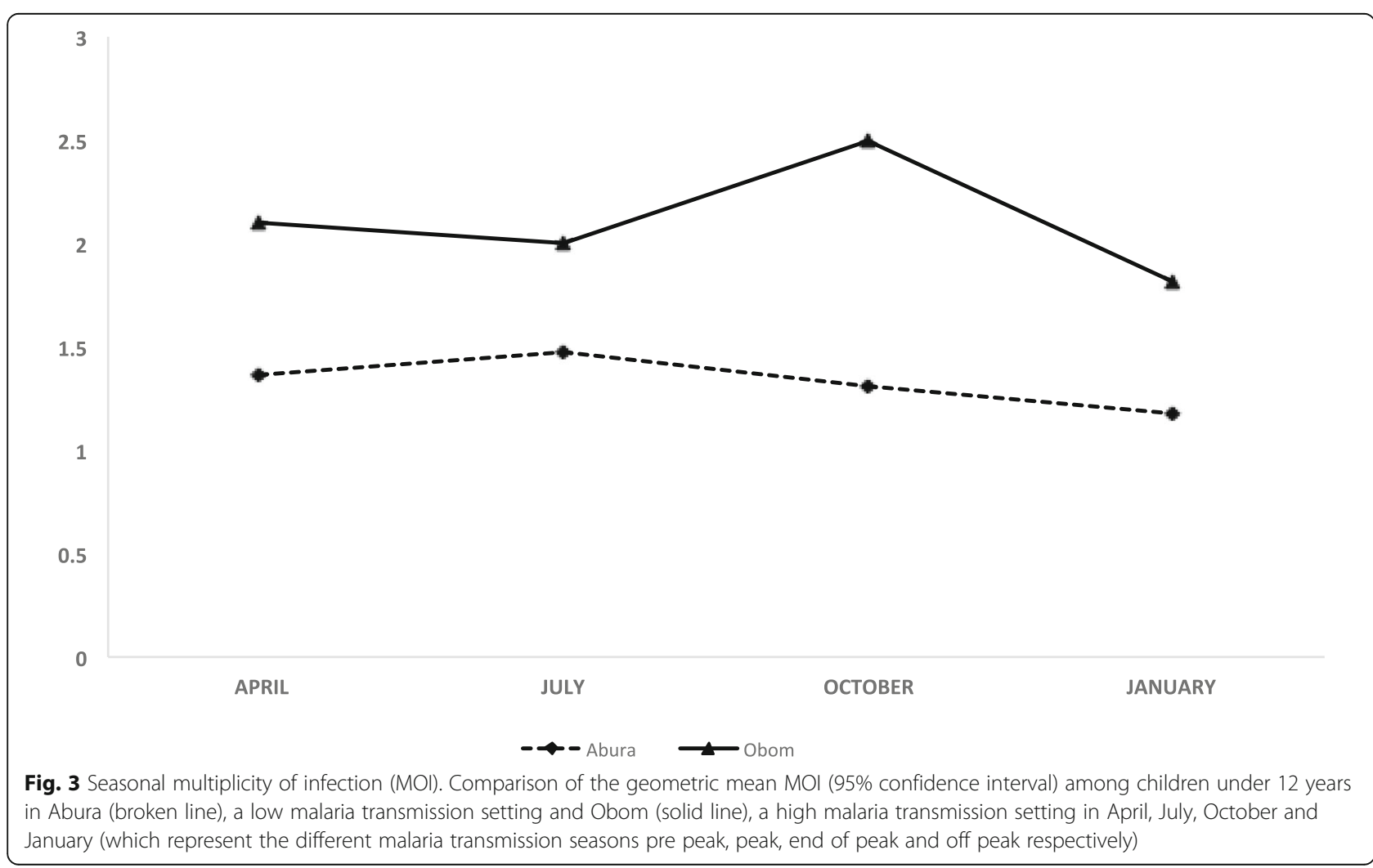


strains and yielded multiple PCR products that belonged to the same as well as different msp 1 (RO33, MAD20 and K1) and msp 2 (3D7 and FC27) allelic families. Each of the multiple msp 1/msp 2 PCR products was considered as a different parasite. The msp 1 and $m s p 2$ alleles were characterized based on the size of the PCR products using $50 \mathrm{bp}$ and $100 \mathrm{bp}$ DNA ladders as size standards. Variations in the sizes of the largest and smallest PCR products within each family specific PCR was noted both msp 1 and $m s p 2$ family members in the two study sites. The approximate size of the smallest and largest alleles of $m s p 1$ was $120 \mathrm{bp}$ and $350 \mathrm{bp}$ respectively for parasites from Obom and $150 \mathrm{bp}$ and 320 bp respectively for parasites from Abura. No obvious trends were observed in the diversity of the smallest and largest sized PCR fragments obtained after msp 1 genotyping in both study sites across the various time points. However, in Obom the largest sized msp 2 fragment, the $400 \mathrm{bp}$ variant persisted from April through to January while in Abura, no trend in the diversity of the largest and smallest sized $m s p 2$ PCR fragments were observed across the time points (Table 2).

In Obom, the proportion of parasites belonging to the R033 of msp 1 reduced from 38.8 to $24.1 \%$ from April to October 2015 and increased slightly in January 2016 (28.7\%). The proportion of parasites belonging to the K1 family reduced from $38.8 \%$ in April 2015 to $24.3 \%$ in July 2015, increased again in October 2015 to $48.8 \%$ and reduced slightly to $43.7 \%$ in January 2016 . The parasites belonging to MAD20 allelic family increased steadily from April (22.4\%) to July 2015 (42.8\%), reduced to $27.1 \%$ in October 2015 and $27.7 \%$ in January 2016 (Fig. 4a). The trend was different than observed in Abura (Fig. 4b). Where, the proportion of parasites with the $\mathrm{RO} 33$ was $59.1 \%$ in April 2015 with a complete absence in October 2015 and a slight increase of $8.1 \%$ in January 2016. The proportion of parasites belonging to the $\mathrm{K} 1$ family increased from $22.7 \%$ in April 2015 to $40.7 \%$ in July 2015 and an absence in October 2015 before increasing again to $27 \%$ in January 2016 being the highest. The proportion of parasites belonging to the MAD20 family decreased from $18.2 \%$ in April 2015 to $4.7 \%$ in July 2015, shot up to $100 \%$ in October 2015 and reduced to $64.9 \%$ in January 2016 (Fig. 4b). A significant association was identified between the prevalence of any particular $m s p 1$ allele and the seasons (time points) in both Obom $\left(x^{2}=27.619, \mathrm{df}=6, p=0.0001\right)$ and Abura (Fisher's Exact test, $P=0.000$ ) (Fig. 4a \& b). Thus the null hypothesis that there was no significant association between the prevalence of a particular $m s p 1$ or $m s p 2$ allele and a particular season was rejected.

In Obom, the proportion of parasites belonging to the 3D7 msp 2 family ranged from 57\% in July 2015 to $43.3 \%$ in January 2016, while the proportion of parasites belonging to the $\mathrm{FC} 27$ family ranged from $43 \%$ in July to

Table 2 Frequencies of variant msp 1 and msp 2 alleles

\begin{tabular}{|c|c|c|c|c|c|c|c|c|c|c|c|c|}
\hline & \multicolumn{3}{|c|}{ APRIL } & \multicolumn{3}{|c|}{ JULY } & \multicolumn{3}{|c|}{ OCTOBER } & \multicolumn{3}{|c|}{ JANUARY } \\
\hline & $N$ & SR (bp) & A (Freq/T) & $N$ & SR (bp) & A (Freq/T) & $N$ & SR (bp) & A (Freq/T) & $N$ & SR (bp) & A (Freq/T) \\
\hline \multicolumn{13}{|l|}{ ABURA } \\
\hline RO33(68) & 3 & $150-300$ & $250(8 / 13)$ & 3 & $200-230$ & $220(47 / 50)$ & 0 & ND & ND & 1 & 250 & $250(3 / 3)$ \\
\hline \multirow[t]{3}{*}{ MAD20(34) } & 2 & $150-250$ & $150(3 / 4)$ & 3 & $200-220$ & $220(2 / 4)$ & 3 & $150-200$ & $150(1 / 3)$ & 3 & $200-250$ & $200(19 / 24)$ \\
\hline & & & & & & & & & 170(1/3); & & & \\
\hline & & & & & & & & & $200(1 / 3)$ & & & \\
\hline K1(53) & 1 & 200 & $200(5 / 5)$ & 9 & $150-300$ & $250(24 / 35)$ & 0 & ND & ND & 6 & $200-320$ & $250(4 / 10)$ \\
\hline 3D7(148) & 7 & $200-600$ & $300(8 / 26)$ & 10 & $200-400$ & $280(21 / 70)$ & 4 & $200-400$ & $300(4 / 8)$ & 6 & $250-410$ & $250(23 / 33)$ \\
\hline FC27(71) & 7 & $250-550$ & $250(4 / 13)$ & 10 & $200-450$ & $300(8 / 30)$ & 3 & $300-500$ & $400(7 / 10)$ & 6 & $300-420$ & $350(5 / 14)$ \\
\hline \multicolumn{13}{|l|}{ OBOM } \\
\hline RO33(152) & 4 & $200-300$ & $250(29 / 33)$ & 3 & $220-270$ & $220(47 / 50)$ & 3 & $200-250$ & $220(35 / 40)$ & 3 & $200-250$ & $220(13 / 29)$ \\
\hline \multirow[t]{3}{*}{ MAD20(154) } & 4 & $150-250$ & $200(9 / 19)$ & 7 & $180-280$ & $220(26 / 65)$ & 3 & $150-220$ & $150(15 / 45)$ & 6 & $150-280$ & $200(12 / 28)$ \\
\hline & & & & & & & & & 200 (15/45); & & & \\
\hline & & & & & & & & & $220(15 / 45)$ & & & \\
\hline K1(196) & 1 & 200 & $200(33 / 33)$ & 8 & $120-270$ & $200(8 / 37) ; 250(8 / 37)$ & 12 & $150-300$ & $270(25 / 81)$ & 7 & $200-300$ & $250(22 / 44)$ \\
\hline 3D7(192) & 9 & $150-400$ & $300(18 / 46)$ & 9 & $250-400$ & $300(16 / 56)$ & 8 & $250-400$ & $350(30 / 61)$ & 5 & $250-400$ & $300(13 / 29)$ \\
\hline FC27(194) & 9 & $200-350$ & $350(17 / 50)$ & 8 & $350-520$ & $450(17 / 49)$ & 10 & $300-580$ & $400(15 / 55)$ & 6 & $300-500$ & $\begin{array}{l}350(11 / 38) ; \\
400(11 / 38)\end{array}$ \\
\hline
\end{tabular}

$N$ total number of different -sized fragments (alleles), representing intra allelic diversity, $S R$ range of fragment sizes in bp, $A$ the most dominant fragment with its frequency of occurrence (Freq) in brackets, ND none detected, $(T)$ total number of fragments detected for the allelic family. A number of samples were infected with mixed infections and contained either parasites belonging to more than one allelic family, multiple variants of the same allelic family or a mixture of both 

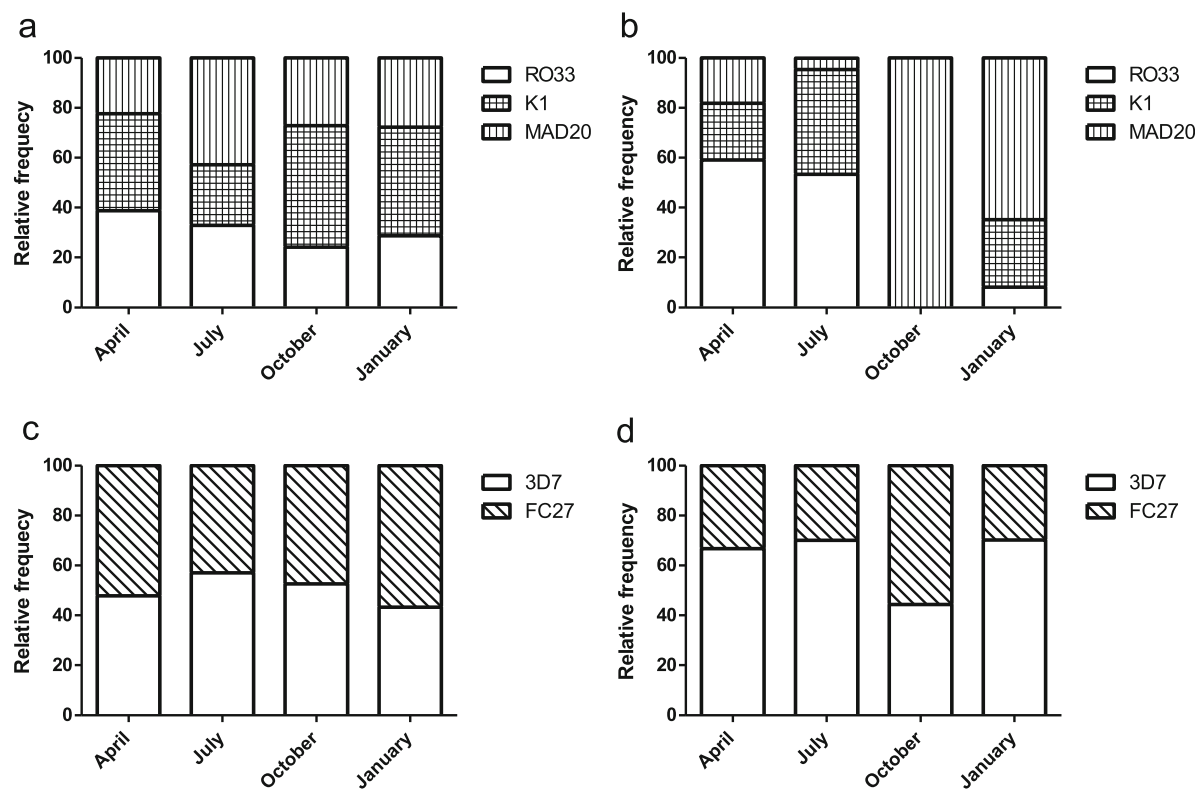

Fig. 4 Relative frequency of merozoite surface protein ( $m s p) 1$ and 2. The percentage of parasites belonging to the different $m s p 1$ (RO33, MAD20 or K1) and $m s p 2$ (3D7 or FC27) families relative to the total percentage of parasites belonging to either msp 1 or msp 2 allelic families in Obom (a and $\mathbf{c}$ ) and Abura (b and $\mathbf{d}$ ) genotyped across the various time points

$56.7 \%$ in January 2016 with slight variation between the seasons (Fig. 4c). In Abura, on the other hand, parasites belonging to the 3D7 family increased from $44.4 \%$ in October 2015 to $70.2 \%$ in January 2016 while the proportion of parasites belonging to the FC27 family decreased from $55.6 \%$ in October 2015 to $29.8 \%$ in January 2016 (Fig. 4d). No association was identified between the seasons (time points) and the prevalence of a particular msp 2 allele in either Obom $\left(\chi^{2}=3.7272, \mathrm{df}=3, P=0.2924\right)$ or Abura (Fisher's Exact test, $P=0.2057$ ) (Fig. 4b, d). Thus the null hypothesis that there was no significant association between the prevalence of a particular msp 1 or $m s p 2$ allele and a particular season was maintained.

\section{Discussion}

This study sought to characterize the genetic diversity of $P$. falciparum and the multiplicity of P. falciparum infections over changing malaria seasons in one community with perennial and high malaria transmission and another with seasonal and low malaria transmission. The most prevalent circulating parasite clones at different time points in different transmission settings were also identified.

In Abura a lot children were lost to follow up at between July and October 2015 (Additional file 2), likely as a result of a number of children changing or dropping out of school at the end of the academic year, which runs from September through to July. Other than in October 2015, where the prevalence of asymptomatic infections in the two sites was similar, the prevalence of asymptomatic infections in Obom was significantly higher than asymptomatic infections in Abura. Asymptomatic parasite carriage in Abura was generally low, except for during the peak season (July 2015) when the prevalence was highest. These results support the positive correlation between rainfall and asymptomatic infections, which has been identified in both high and low malaria transmission settings [36, 37] and also the fact that malaria in Abura is low and seasonal. July 2015 registered the lowest proportion of asymptomatic infections in Obom, but was not significantly different from the other time points $(p>0.05$, Dunn's Multiple comparison test). This is to be expected in perennial transmission settings, where mosquito vectors and malaria transmission only vary slightly between seasons [46].

The amplification efficiencies for both $m s p 1$ and $m s p$ 2 were lower in Abura compared to Obom most likely because the gDNA extracted from the DBS contained fewer parasites due to lower parasite densities identified in samples from Abura compared to Obom [47]. Generally, PCR amplification efficiencies for single copy genes including msp 1 and msp 2 are more greatly reduced in the presence of low template concentration than high copy number genes, including the $18 \mathrm{~s}$ rRNA gene [48] The geometric mean MOI for infections in Abura at each time point was significantly lower than that determined in Obom (Fig. 3), most likely because the frequency of infectious mosquito bites in high transmission settings, that could result in additional inoculum of variant parasites is higher than in lower transmission settings [49]. This finding supports general notion that 
Low transmission settings are commonly associated with reduced MOI in malaria endemic countries [50, 51]. The geometric mean MOI differed significantly across the time points in Abura (Fig. 3), most likely because the mosquito vector population varied between those time points as is expected for communities in semi-urban settings [52]. The low geometric mean MOI identified for Abura, the low transmission setting is consistent with a previous report from Ghana where the MOI recorded in areas with lower malaria transmission were found to be lower than high transmission areas especially during the peak season [53]. The low MOI during the peak season in Obom (Fig. 3) could be as a result of an artifact caused by the presence of a single dominant clone overshadowing the amplification of low-density minor parasite isolates as has been reported in Senegal where the most abundant msp 1 and 2 alleles interfered with the amplification of the less abundant one $[54,55]$. A recent report from Central Ghana found the wet season (peak malaria season) to be associated with a lower MOI than the preceding dry season [28]. A similarly low geometric mean MOI was identified in Abura (Fig. 3).

There was a wide range of variability in the relative frequencies of different $m s p 1$ alleles (inter allelic diversity) as well as the dominance of any $m s p 1$ allele across the seasons and between the two transmission settings (Table 2). Parasites circulating in both Obom and Abura were predominantly RO33 in April, but $\mathrm{K} 1$ in Obom (Fig. 4a) and MAD20 in Abura in October. The K1 allele has similarly been reported to be prevalent in high transmission settings amongst asymptomatic children [38] [46]. The distribution of parasites with different 3D7 and FC27 alleles of msp 2 was similar over the course of the study in both Obom and Abura. The approximate 1:1 ratio of 3D7:FC27 msp 2 alleles circulating in Obom across the different seasons (Fig. 4c) seems to be a characteristic of parasites circulating in high transmission settings as a similar ratio was observed in Kintampo, a high transmission setting in Ghana between 2009 and 2010 [28]. The 3D7:FC27 ratio of 3:2 in Abura was similarly constant across the different seasons, except for in October (Fig. 4d) where parasite prevalence was extremely low $(13.7 \%)$.

The variations in $m s p$ fragment size has been suggested to be the result of a number of genetic events including insertion-deletion mutations and recombination events [56]. The sizes of the msp 1 and msp 2 alleles ranged from $120 \mathrm{bp}$ to $350 \mathrm{bp}$ and $150 \mathrm{bp}$ to $600 \mathrm{bp}$ respectively (Table 2) and were similar to that previously reported from Gezira State in Central Sudan and in Kolla-Shele area in Southwest Ethiopia where the band sizes for the $m s p 1$ and $m s p 2$ alleles ranged from 150 to 300 bp for KI, 100-300 bp for RO33, 100-380 bp for MAD20, 250-750 bp for 3D7 and 200-700 bp for FC27
[56-58]. An earlier study conducted in Kintampo in central Ghana identified msp 2 alleles with as high as 900 bp [28], which were not encountered in this study. This suggests that different $P$. falciparum parasites circulate in central and southern Ghana, which is not surprising as parasite diversity has been suggested to be constantly changing and distinct in different individuals, populations and seasons [10,59].

More elaborate studies across different transmission settings are needed to better understand parasite complexity in Ghana.

\section{Limitations}

The resolution of agarose gel electrophoresis does not permit distinction between PCR fragments that differ by a few base pairs, which can result in fewer alleles being detected and consequently, a lower reported MOI. The parasite diversity and MOI recorded in this study could be common to all parasitemic children in the selected communities as no symptomatic children were enrolled in this study for comparison.

\section{Conclusions}

This study shows that seasonal variations in parasite diversity can be better estimated by msp 1 genotyping rather than $m s p 2$ due to the constantly changing relative intra allelic frequencies observed in $m s p 1$ and fact that the dominance of any msp 2 allele was dependent on the transmission setting but not on the season as opposed to the dominance of any msp 1 allele, which was dependent on both the season and the transmission setting.

\section{Additional files}

Additional file 1: Primers used for $P$. falciparum detection and genotying. (DOCX $17 \mathrm{~kb}$ )

Additional file 2: Plasmodium falciparum parasite carriage in study participants. (DOCX $15 \mathrm{~kb})$

\section{Abbreviations}

DBS: Dried blood spot; gDNA: Genomic DNA; MOI: Multiplicity of infection; msp: Merozoite surface protein; PBS: Phosphate buffered saline

\section{Acknowledgments}

The authors are grateful to the children who participated in this study as well as their guardians for granting consent. We are also grateful to Dr. KA Kusi for helping with the statistical analysis. We also thank MR4/BEIR for the generous donation of all the gDNA controls used in this study.

\section{Funding}

This project was supported in part by the Ghana government Book and Research allowance. "The funders had no role in study design, data collection and analysis, decision to publish, or preparation of the manuscript".

Availability of data and materials

The data sets used and /or analyzed during the current study are available from the corresponding author on request.' 


\section{Authors' contributions}

LEA designed the study; LEA and JA performed the statistical analysis; JA and BF performed the experiments. LEA, RA-T and JA wrote and revised the final manuscript. All authors read and approved the final manuscript.

\section{Ethics approval and consent to participate}

Ethical clearance for this study was obtained from the Institutional Review Board of the Noguchi Memorial Institute for Medical Research (NMIMR). Approval to conduct the study was also granted by the Regional and District Directors of Education that have oversight over primary schools from which study participants were recruited. The study was explained to the parents / guardians of the school children prior to initiating the study. Only children whose parent / guardian provided written informed consent were recruited into the study.

\section{Consent for publication}

Not applicable.

\section{Competing interests}

The authors declare that they have no competing interests.

\section{Publisher's Note}

Springer Nature remains neutral with regard to jurisdictional claims in published maps and institutional affiliations.

\section{Received: 16 January 2018 Accepted: 21 August 2018} Published online: 29 August 2018

\section{References}

1. Marsh K, Snow RW. Host-parasite interaction and morbidity in malaria endemic areas. Philos Trans R Soc Lond B Biol Sci. 1997;352(1359):1385-94.

2. Konaté L, Zwetyenga J, Rogier C, Bischoff E, Fontenille D, Tall A, Spiegel A, Trape J-F, Mercereau-Puijalon O. 5. Variation of plasmodium falciparum msp1 block 2 and msp2 allele prevalence and of infection complexity in two neighbouring Senegalese villages with different transmission conditions. Trans R Soc Trop Med Hyg. 1999:93:21-8.

3. Smith T, Beck H-P, Kitua A, Mwankusye S, Felger I, Fraser-Hurt N, Irion A, Alonso P, Teuscher T, Tanner M. 4. Age dependence of the multiplicity of plasmodium falciparum infections and of other malariological indices in an area of high endemicity. Trans R Soc Trop Med Hyg. 1999;93:15-20.

4. Ntoumi F, Contamin H, Rogier C, Bonnefoy S, Trape J-F, Mercereau-Puijalon O. Age-dependent carriage of multiple plasmodium falciparum merozoite surface antigen-2 alleles in asymptomatic malaria infections. Am J Trop Med Hyg. 1995;52(1):81-8

5. Karl S, White MT, Milne GJ, Gurarie D, Hay SI, Barry AE, Felger I, Mueller I. Spatial effects on the multiplicity of plasmodium falciparum infections. PLoS One. 2016;11(10):e0164054.

6. Wootton JC, Feng X, Ferdig MT, Cooper RA, Mu J, Baruch DI, Magill AJ, X-Z S. Genetic diversity and chloroquine selective sweeps in plasmodium falciparum. Nature. 2002:418(6895):320-3.

7. Ouattara A, Laurens MB. Vaccines against malaria. Clin Infect Dis. 2014;60(6): 930-6.

8. Childs LM, Prosper OF. Simulating within-vector generation of the malaria parasite diversity. PLoS One. 2017;12(5):e0177941.

9. Pumpaibool T, Arnathau C, Durand P, Kanchanakhan N, Siripoon N, Suegorn A, Sitthi-amorn C, Renaud F, Harnyuttanakorn P. Genetic diversity and population structure of plasmodium falciparum in Thailand, a low transmission country. Malar J. 2009;8(1):155.

10. Anderson TJ, Haubold B, Williams JT, Estrada-Franco $\S J G$, Richardson L, Mollinedo R, Bockarie M, Mokili J, Mharakurwa S, French N. Microsatellite markers reveal a spectrum of population structures in the malaria parasite plasmodium falciparum. Mol Biol Evol. 2000;17(10):1467-82.

11. Machado RL, voa MMP, Calvosa VS, Ferreira MU, Rossit AR, EJd S, Conway DJ. Genetic structure of plasmodium falciparum populations in the Brazilian Amazon region. J Infect Dis. 2004;190(9):1547-55.

12. Mita T, Jombart T. Patterns and dynamics of genetic diversity in plasmodium falciparum: what past human migrations tell us about malaria. Parasitol Int. 2015:64(3):238-43.

13. Arnott A, Barry AE, Reeder JC. Understanding the population genetics of plasmodium vivax is essential for malaria control and elimination. Malar J. 2012;11(1):14.
14. Haddad D, Snounou G, Mattei D, Enamorado IG, Figueroa J, Ståhl S, Berzins K. Limited genetic diversity of plasmodium falciparum in field isolates from Honduras. Am J Trop Med Hyg. 1999;60(1):30-4.

15. Babiker HA, Lines J, Hill WG, Walliker D. Population structure of plasmodium falciparum in villages with different malaria endemicity in East Africa. Am J Trop Med Hyg. 1997;56(2):141-7.

16. Peyerl-Hoffmann G, Jelinek T, Kilian A, Kabagambe G, Metzger W, Von Sonnenburg F. Genetic diversity of plasmodium falciparum and its relationship to parasite density in an area with different malaria endemicities in West Uganda. Tropical Med Int Health. 2001;6(8):607-13.

17. Babiker HA, Ranford-Cartwright LC, Walliker D. 3. Genetic structure and dynamics of plasmodium falciparum infections in the Kilombero region of Tanzania. Trans R Soc Trop Med Hyg. 1999;93:11-4.

18. Smith DL, Drakeley CJ, Chiyaka C, Hay SI. A quantitative analysis of transmission efficiency versus intensity for malaria. Nat Commun. 2010;1:108.

19. Smith DL, Battle KE, Hay SI, Barker CM, Scott TW, McKenzie FE. Ross, Macdonald, and a theory for the dynamics and control of mosquitotransmitted pathogens. PLoS Path. 2012;8(4):e1002588.

20. Karunamoorthi K. Malaria vaccine: a future hope to curtail the global malaria burden. Int J Prev Med. 2014;5(5):529.

21. Srimath-Tirumula RCPK, Neelapu NRR, Sidagam N. Association of climatic variability, vector population and malarial disease in district of Visakhapatnam, India: a modeling and prediction analysis. PLoS One. 2015. 10(6):e0128377.

22. Ntoumi F, Ngoundou-Landji J, Luty A, Dubreuil G, Millet P. Allelic polymorphism of plasmodium falciparum MSP-2 gene in blood samples from Gabonese children. Bull Soc Pathol Exot. 2001;94(2 Pt 2):183-7.

23. Krogstad DJ, Koita OA, Diallo M, Gerone JL, Poudiougou B, Diakité M, Touré YT. Molecular incidence and clearance of plasmodium falciparum infection. Malar J. 2015;14(1):415.

24. Auburn S, Campino S, Miotto O, Djimde AA, Zongo I, Manske M, Maslen G, Mangano V, Alcock D, Maclnnis B. Characterization of within-host plasmodium falciparum diversity using next-generation sequence data. PLoS One. 2012;7(2):e32891.

25. Viriyakosol S, Siripoon N, Petcharapirat C, Petcharapirat P, Jarra W, Thaithong S, Brown K, Snounou G. Genotyping of Plasmodium falciparum isolates by the polymerase chain reaction and potential uses in epidemiological studies. Bull World Health Organ. 1995;73(1):85.

26. Dobaño C, Rogerson SJ, Taylor TE, McBride JS, Molyneux ME. Expression of merozoite surface protein markers by plasmodium falciparum-infected erythrocytes in peripheral blood and tissues of children with fatal malaria. Infect Immun. 2007;75(2):643-52.

27. Organization WH. Methods and techniques for clinical trials on antimalarial drug efficacy: genotyping to identify parasite populations: informal consultation organized by the Medicines for Malaria Venture and cosponsored by the World Health Organization, 29-31 May 2007, Amsterdam, The Netherlands. 2008.

28. Botwe AK, Asante KP, Adjei G, Assafuah S, Dosoo D, Owusu-Agyei S. Dynamics in multiplicity of plasmodium falciparum infection among children with asymptomatic malaria in Central Ghana. BMC Genet. 2017; 18(1):67.

29. Saha P, Ganguly S, Maji AK. Genetic diversity and multiplicity of infection of plasmodium falciparum isolates from Kolkata, West Bengal, India. Infect Genet Evol. 2016:43:239-44.

30. Soe TN, Wu Y, Tun MW, Xu X, Hu Y, Ruan Y, Win AYN, Nyunt MH, Mon NCN, Han KT. Genetic diversity of plasmodium falciparum populations in southeast and western Myanmar. Parasit Vectors. 2017;10(1):322.

31. Mustafa SO, Hamid MMA, Aboud MA, Amin M, Muneer MS, Yasin K, Mahgoub NS, El Bagir NM. Genetic diversity and multiplicity of plasmodium falciparum merozoite surface protein 2 in field isolates from Sudan. F1000Res. 2017;6:1790. https://doi.org/10.12688/f1000research.12585.1.

32. Stoler J, Delimini RK, Bonney JK, Oduro AR, Owusu-Agyei S, Fobil JN, Awandare GA. Evidence of recent dengue exposure among malaria parasite-positive children in three urban centers in Ghana. Am J Trop Med Hyg. 2015;92(3):497-500.

33. Musapa M, Kumwenda T, Mkulama M, Chishimba S, Norris DE, Thuma PE, Mharakurwa S. A simple Chelex protocol for DNA extraction from Anopheles spp. J Vis Exp. 2013;71:e3281. https://doi.org/10.3791/3281.

34. Duah NO, Matrevi SA, Quashie NB, Abuaku B, Koram KA. Genetic diversity of plasmodium falciparum isolates from uncomplicated malaria cases in Ghana over a decade. Parasit Vectors. 2016;9(1):416. 
35. Kateera F, Nsobya SL, Tukwasibwe S, Mens PF, Hakizimana E, Grobusch MP Mutesa L, Kumar N, Vugt M. Malaria case clinical profiles and plasmodium falciparum parasite genetic diversity: a cross sectional survey at two sites of different malaria transmission intensities in Rwanda. Malar J. 2016;15(1):237.

36. Amoah LE, Acquah FK, Ayanful-Torgby R, Oppong A, Abankwa J, Obboh EK, Singh SK, Theisen M. Dynamics of anti-MSP3 and Pfs 230 antibody responses and multiplicity of infection in asymptomatic children from southern Ghana. Parasit Vectors. 2018;11(1):13.

37. Service GS. Cape Coast Municipality. In: 2010 Population \& Housing Consensus: District Analytical Report. Ghana; 2014.

38. Service GS. Ga South Municipality. In: 2010 Population \& Housing Consensus: District Analytical Report. Ghana; 2014.

39. Ayanful-Torgby R, Oppong A, Abankwa J, Acquah F, Williamson KC, Amoah LE. Plasmodium falciparum genotype and gametocyte prevalence in children with uncomplicated malaria in coastal Ghana. Malar J. 2016;15(1): 592.

40. Musapa M, Kumwenda T, Mkulama M, Chishimba S, Norris DE, Thuma PE, Mharakurwa S. A simple Chelex protocol for DNA extraction from Anopheles spp. J Vis Exp. 2013;71:e3281.

41. Amoah LE, Nuvor SV, Obboh EK, Acquah FK, Asare K, Singh SK, Boampong $\mathrm{JN}$, Theisen M, Williamson KC. Natural antibody responses to plasmodium falciparum MSP3 and GLURP(R0) antigens are associated with low parasite densities in malaria patients living in the central region of Ghana. Parasit Vectors. 2017;10(1):395

42. Boonma P, Christensen PR, Suwanarusk R, Price RN, Russell B. Comparison of three molecular methods for the detection and speciation of plasmodium vivax and plasmodium falciparum. Malar J. 2007;6(1):124.

43. Organization WH. Recommended genotyping procedures (RGPs) to identify parasite populations. In: Developed after an informal consultation organized by the Medicines for Malaria Venture and cosponsored by the World Health Organization; 2007.

44. Abagna HB, Acquah FK, Okonu R, Aryee NA, Theisen M, Amoah LE. Assessment of the quality and quantity of naturally induced antibody responses to EBA175RIII-V in Ghanaian children living in two communities with varying malaria transmission patterns. Malar J. 2018;17(1):14. https://doi. org/10.1186/s12936-017-2167-3

45. Kobbe R, Neuhoff R, Marks F, Adjei S, Langefeld I, Von Reden C, Adjei O, Meyer CG, May J. Seasonal variation and high multiplicity of first plasmodium falciparum infections in children from a holoendemic area in Ghana, West Africa. Tropical Med Int Health. 2006;11(5):613-9.

46. Elissa N, Migot-Nabias F, Luty A, Renaut A, Toure F, Vaillant M, Lawoko M, Yangari P, Mayombo J, Lekoulou F, et al. Relationship between entomological inoculation rate, plasmodium falciparum prevalence rate, and incidence of malaria attack in rural Gabon. Acta Trop. 2003;85(3):35561.

47. Ayanful-Torgby R, Quashie NB, Boampong JN, Williamson KC, Amoah LE. Seasonal variations in plasmodium falciparum parasite prevalence assessed by varying diagnostic tests in asymptomatic children in southern Ghana. PLoS One. 2018;13(6):e0199172.

48. Hofmann N, Mwingira F, Shekalaghe S, Robinson LJ, Mueller I, Felger I. Ultrasensitive detection of plasmodium falciparum by amplification of multicopy subtelomeric targets. PLoS Med. 2015;12(3):e1001788.

49. Das S, Muleba M, Stevenson JC, Pringle JC, Norris DE. Beyond the entomological inoculation rate: characterizing multiple blood feeding behavior and plasmodium falciparum multiplicity of infection in Anopheles mosquitoes in northern Zambia. Parasit Vectors. 2017;10(1):45.

50. Atroosh WM, Al-Mekhlafi HM, Mahdy MA, Saif-Ali R, Al-Mekhlafi AM, Surin J. Genetic diversity of plasmodium falciparum isolates from Pahang, Malaysia based on MSP-1 and MSP-2 genes. Parasit Vectors. 2011;4(1):233.

51. Mohammed H, Kassa M, Assefa A, Tadesse M, Kebede A. Genetic polymorphism of Merozoite surface Protein-2 (MSP-2) in plasmodium falciparum isolates from Pawe District, north West Ethiopia. PLoS One. 2017; 12(5):e0177559.

52. Amoah LE, Opong A, Ayanful-Torgby R, Abankwa J, Acquah FK. Prevalence of G6PD deficiency and plasmodium falciparum parasites in asymptomatic school children living in southern Ghana. Malar J. 2016;15(1):388.

53. Agyeman-Budu A, Brown C, Adjei G, Adams M, Dosoo D, Dery D, Wilson M, Asante KP, Greenwood B, Owusu-Agyei S. Trends in multiplicity of plasmodium falciparum infections among asymptomatic residents in the middle belt of Ghana. Malar J. 2013;12(1):22.
54. Contamin H, Fandeur T, Bonnefoy S, Skouri F, Ntoumi F, Mercereau-Puijalon O. PCR typing of field isolates of plasmodium falciparum. J Clin Microbiol. 1995;33(4):944-51.

55. Magesa SM. Malaria Parasite Dynamics: Epidemiology, Allelic Diversity and Turnover Rates of Plasmodium falciparum Infections in Tanzanian Children: Ph. D. Thesis. Denmark: Department of Population Biology, Zoological Institute, University of Copenhagen; 1999.

56. Hamid MMA, Elamin AF, Albsheer MMA, Abdalla AA, Mahgoub NS, Mustafa SO, Muneer MS, Amin M. Multiplicity of infection and genetic diversity of plasmodium falciparum isolates from patients with uncomplicated and severe malaria in Gezira State, Sudan. Parasit Vectors. 2016;9(1):362.

57. Hamid MMA, Mohammed SB, El Hassan IM. Genetic diversity of plasmodium falciparum field isolates in Central Sudan inferred by PCR genotyping of merozoite surface protein 1 and 2. N Am J Med Sci. 2013;5(2):95.

58. Mohammed H, Mindaye T, Belayneh M, Kassa M, Assefa A, Tadesse M, Woyessa A, Mengesha T, Kebede A. Genetic diversity of plasmodium falciparum isolates based on MSP-1 and MSP-2 genes from Kolla-Shele area, Arbaminch Zuria District, Southwest Ethiopia. Malar J. 2015;14(1):73.

59. Hay SI, Sinka ME, Okara RM, Kabaria CW, Mbithi PM, Tago CC, Benz D, Gething PW, Howes RE, Patil AP. Developing global maps of the dominant Anopheles vectors of human malaria. PLoS Med. 2010;7(2):e1000209.
Ready to submit your research? Choose BMC and benefit from:

- fast, convenient online submission

- thorough peer review by experienced researchers in your field

- rapid publication on acceptance

- support for research data, including large and complex data types

- gold Open Access which fosters wider collaboration and increased citations

- maximum visibility for your research: over $100 \mathrm{M}$ website views per year

At BMC, research is always in progress.

Learn more biomedcentral.com/submissions 